\title{
Zorba el griego \\ o cuando Nietzsche bailó el syrtaki ${ }^{1}$
}

\author{
Zorba the Greek \\ or When Nietzsche Danced the Syrtaki
}

\author{
Alejandro Valverde García \\ IES Santísima Trinidad de Baeza \\ allenvalgar@hotmail.com \\ ORCID ID: 0000-0001-7357-2008
}

\begin{abstract}
Resumen: Tras el éxito obtenido a nivel internacional por su trasposición fílmica de la tragedia de Eurípides Electra, el director Michael Cacoyannis adapta para el cine una famosa novela del escritor cretense Nikos Kazantzakis, logrando crear una obra de arte completamente independiente de su fuente literaria, a la que supera incluso en popularidad. En este artículo se analiza esta película, Zorba el griego, a la luz de la lectura del texto que la inspira, pero también de otros referentes culturales presentes en ella, como son el antiguo drama ático, representado en la pantalla a través de la actriz griega Irene Papas, el pensamiento existencialista de Nietzsche, el neorrealismo italiano y el cine de la época dorada de Hollywood.
\end{abstract}

Palabras clave: literatura neohelénica, cine griego, tragedia griega, Nikos Kazantzakis, Michael Cacoyannis, Eurípides, Zorba el griego.

\begin{abstract}
After the international success obtained by his filmic transposition of the tragedy of Euripides, Electra, director Michael Cacoyannis adapts for the cinema a famous novel by Cretan writer Nikos Kazantzakis, creating a work of art completely independent, which even surpasses the popularity of its literary source. This article analyses this film, Zorba the Greek, having into account not only the reading of the text that inspires it, but also other cultural references present in it such as the old Attic drama, represented on the screen by the Greek actress Irene Papas, Nietzsche's existentialist thinking, Italian Neorealism and the films of the golden years of Hollywood.
\end{abstract}

Key Words: neo-Hellenic literature, Greek cinema, Greek tragedy, Nikos Kazantzakis, Michael Cacoyannis, Euripides, Zorba the Greek.

${ }^{1}$ El presente trabajo se enmarca en el Proyecto de Innovación Docente de la Universidad de Valladolid PID-67 Materiales audiovisuales sobre el mundo griego: elaboración y análisis. Agradecemos sinceramente todas las observaciones y correcciones aportadas por Miguel Dávila y Amor López durante la gestación del texto. 
«Zorba me ha enseñado a amar la vida y a no temer a la muerte»

(Nikos Kazantzakis)

Zorba el griego (Zorba the Greek, 1964) es, incomprensiblemente, de todas las adaptaciones cinematográficas realizadas a partir de las novelas escritas por Nikos Kazantzakis, la menos estudiada desde el ámbito académico, salvando el caso de varios profesores griegos especializados en literatura neohelénica y su relación con la gran pantalla. Este filme, cuya repercusión internacional es de sobra conocida, va unido de forma indisoluble al nombre del actor protagonista, Anthony Quinn, a quien el cine considerará a partir de ese momento el griego por antonomasia, a pesar de ser de origen mexicano ${ }^{2}$. También Mikis Theodorakis, que compuso una excelente banda sonora sobre temas que ya había utilizado en otras películas griegas anteriores, razón por la que no se le pudo nominar al Oscar de Hollywood (Triantafyllides, 2014: 99), se hizo mundialmente famoso por ese syrtaki de la secuencia final, un broche de oro memorable que, como analizaremos más adelante, cambió por completo el sentido de la obra original hasta convertirse en un canto a la vida, al optimismo y al triunfo de la compenetración entre lo dionisíaco y lo apolíneo (Mitropoulos, 1968: 77). Pero, por debajo de los aspectos más conocidos del filme, tejiendo los hilos de la narración y siempre pendiente hasta de los últimos detalles, nos encontramos ante un genio del cine del siglo $\mathrm{XX}$, un director de origen chipriota que ya había demostrado su capacidad indiscutible para bordar las adaptaciones fílmicas de obras literarias, especialmente de las tragedias griegas (Hadjikyriacou, 2015: 113).

Michael Cacoyannis ${ }^{3}$, el mayor representante del llamado nuevo cine griego junto a Theo Angelopoulos, procedía de una familia acomodada relacionada con el mundo de las leyes. Gracias a la decisión de su padre de que estudiase la carrera de Derecho en Londres pudo conocer de cerca el Old Vic y hacer sus pinitos en la emisión de distintos programas radiofónicos para la BBC y en algunas representaciones teatrales actuando como protagonista. Estas experiencias le hacen descubrir su verdadera vocación. En adelante luchará por abrirse camino en el mundo del cine, pero no dedicándose a la interpretación sino escribiendo guiones que él mismo se encargará de filmar, supervisar y editar, algo que irá en contra del sistema

${ }^{2}$ De hecho, pasados los años, Anthony Quinn volverá a encarnar papeles de hombres griegos en filmes como Sueño de reyes (A Dream of Kings, Daniel Mann, 1969) o El griego de oro (The Greek Tycoon, J. Lee Thompson, 1978), donde da vida al armador multimillonario Aristóteles Onassis.

${ }^{3}$ Para una información más exhaustiva sobre la producción cinematográfica de este director, con una bibliografía actualizada, consultar Valverde 2013. 
de trabajo impuesto por los grandes estudios cinematográficos norteamericanos.

Zorba el griego se estrenó por todo lo alto el año 1964, un momento de esplendor para el cine griego. Podríamos atrevernos a afirmar que Grecia estaba de moda en Hollywood. El caso de la actriz Katina Paxinou, quien recibió un Oscar de la Academia por su interpretación en Por quién doblan las campanas (For Whom the Bells Tolls, Sam Wood, 1943) y dio vida a la Clitemnestra moderna del melodrama $A$ Electra le sienta bien el luto (Mourning Becomes Electra, Dudley Nichols, 1947), podría considerarse como un hecho bastante puntual en la década de los años 40. Ella, una gran dama de la escena neohelénica, junto a su marido, el también actor Alexis Minotis, que llegó a trabajar a las órdenes de Alfred Hitchcock en Encadenados (Notorious, 1946), hicieron en Estados Unidos una breve pero brillante carrera como actores de reparto antes de volver a su Grecia natal, en cuyos escenarios brillaron recreando para los espectadores los grandes textos del teatro griego antiguo.

Griego, aunque nacido en Estambul, era también el director Elia Kazan, quien en su película más autobiográfica, América, América (America America, 1963), narraba las peripecias de un joven obligado por el hambre y la pobreza a exiliarse en busca de un futuro mejor. Él mismo desde el Actors Studio había introducido en el mercado cinematográfico norteamericano a su compatriota Irene Papas, que fue lanzada en 1956 por la MetroGoldwyn-Mayer sustituyendo a Grace Kelly en el western La ley de la horca (Tribute to a Bad Man, Robert Wise), y en 1961 el Oscar al mejor actor secundario recayó en el bailarín de ascendencia griega George Chakiris por su interpretación en el musical West Side Story (Robert Wise y Jerome Robbins). Pero la película que sin duda marcó un hito fundamental en la historia del cine griego por su repercusión internacional fue sin lugar a dudas Nunca en Domingo (Never on Sunday / Poté tin Kyriakí, 1960), rodada en el puerto del Pireo con un presupuesto muy ajustado por el director norteamericano Jules Dassin y la que sería su mujer, la actriz y futura ministra de cultura del gobierno griego Melina Mercouri ${ }^{4}$. La canción de Manos Hadjidakis Los niños del Pireo (Ta pediá tu Pireá) alcanzará fama mundial y Grecia empezará a aparecer como marca de calidad en el mercado cinematográfico extranjero (Basea, 2015: 70), como lo demuestra el hecho de que en dos años consecutivos este país consiga lo que nunca antes se había visto, a saber, encontrarse entre los países nominados al Oscar a la mejor película de habla no inglesa, con Electra (Elektra, 1962) de Cacoyannis y con

${ }^{4}$ Una curiosa crítica firmada por Rozita Sokou en el periódico griego Kazimeriní $(17 / 03 / 1965)$ tras el estreno en Grecia de Zorba el griego establece varios paralelismos entre el film y Nunca en Domingo hablando de Zorba como una Ilya con pantalones. Según ella, en ambas producciones, destinadas fundamentalmente al público norteamericano, se ridiculiza la cultura helénica con muchos elementos misóginos que se apartan de la realidad (Agathos, 2007 115). 


\section{Alejandro Valverde García}

Ta kokkina fanaria (1963) de Vassilis Georgiadis, una hazaña que ambos directores volverán a lograr en 1977 y en 1966, respectivamente. Esta es la razón por la que ya nadie se extrañó cuando Zorba el griego obtuvo siete nominaciones al Oscar de aquel año, tres de las cuales recaían directamente sobre Michael Cacoyannis (mejor película, dirección y guion adaptado). Curiosamente ni él, ni Anthony Quinn (nominado como mejor actor protagonista), ni Irene Papas o Mikis Theodorakis fueron galardonados, sino que la Academia premió el impresionante trabajo realizado por Lila Kedrova (mejor actriz de reparto), Walter Lassally (mejor fotografía en blanco y negro) y un jovencísimo Vassilis Fotopoulos (mejor dirección artística en blanco y negro). Sin embargo, el hecho de competir con las grandes superproducciones norteamericanas, así como otras cinco nominaciones al Globo de Oro y cuatro más a los premios BAFTA de Londres, sirvió de impulso para que el éxito de la película siguiese su curso imparable.

En los títulos de crédito los espectadores leían que el guion del filme se basaba en una novela de Nikos Kazantzakis, pero dudamos de que fuesen muchos los que hubieran leído la obra original con anterioridad. En esta ocasión, como suele suceder frecuentemente, fue más bien la popularidad de la película la que animó al público a comprar y leer el texto en alguna traducción más asequible, puesto que pocos seguramente conocían el griego moderno. Vida y andanzas de Alexis Zorba (Bíos ke politía tu Alexi Zorbá) se había publicado en Grecia a finales del año 1946 en la editorial ateniense Dimitrakou. Su primera traducción al inglés, ya con el nombre de Zorba the Greek, la realizó Carl Wildman en $1952^{5}$ y, dos años después, recibió en Francia el Premio al mejor libro extranjero. A Kazantzakis le interesó desde siempre el cine como forma artística. Él mismo escribió varios guiones cinematográficos (Bien, 2000: 162) y su aspiración más profunda era la de convertir en sencillas imágenes complejos conceptos filosóficos, de forma que podemos asegurar que el cine influyó mucho en su forma de dar cuerpo y redactar sus propias novelas (Taylor, 1980: 158). Recordemos en este punto que en la novela pone en boca de Alexis Zorba la siguiente afirmación: «lo que no podemos expresar con palabras lo haremos con los ojos, con las manos... ${ }^{6}$, algo que materializará de forma magistral Cacoyannis en el filme con la selección de planos y el uso de la cámara (Kolonias, 1995: 154).

Cuando Jules Dassin, animado por Melina Mercouri, propuso al novelista cretense realizar una adaptación de Cristo de nuevo crucificado ( $O$ Jristós xanastavrónete, 1948), este se mostró entusiasmado con la idea. De hecho, siguió el rodaje de El que debe morir (Celui qui doit mourir, 1957) con

${ }^{5}$ En «The Top 100 Books of all time» de The Guardian (8/08/2002) se incluye la novela Zorba el griego junto a la Ilíada y a la Odisea de Homero, el Edipo rey de Sófocles, la Medea de Eurípides, las Metamorfosis de Ovidio y El Quijote de Cervantes (Agathos, 2007: 90).

${ }^{6}$ En nuestras citas seguiremos siempre la traducción de Selma Ancira recogida en la bibliografía final. 
gran interés y se presentó al estreno del filme en Cannes poco antes de morir. En cuanto a Vida y andanzas de Alexis Zorba nos consta que el actor Fredric March y su esposa Florence Eldridge habían propuesto a Elia Kazan que comprase los derechos de la novela para escribir el guion cinematográfico, pero parece que el proyecto se frustró. De igual forma, en 1954 corrieron rumores de que Burt Lancaster daría vida a Zorba en la gran pantalla ${ }^{7}$ y también Dassin pensó en hacer la película dando el papel protagonista al actor soviético Nikolai Cherkasov (Agathos, 2007: 91). Pero al final fue Michael Cacoyannis el que, en el año 1963, terminó negociando con la viuda y heredera del autor, Eleni Kazantzaki, los derechos sobre el texto para reelaborar la historia, trasladándola al lenguaje cinematográfico. En esta decisión tuvo un papel fundamental la actriz Irene Papas, con la que había triunfado a nivel internacional el año anterior gracias a la adaptación de la tragedia de Eurípides Electra, un trabajo por el que había sido premiado en el Festival de Cannes.

Cacoyannis y Kazantzakis, que se conocieron personalmente en Londres durante la Segunda Guerra Mundial en uno de esos programas radiofónicos de la BBC (Triantafyllides, 2014: 59; Siafkos, 2009: 40), tenían muchos puntos en común. Aparte de su gran pasión por el cine, ambos procedían de las periferias insulares de Grecia (Chipre y Creta, respectivamente) y conocían perfectamente no solo la realidad helénica sino de los países europeos más poderosos y avanzados. Además, vivieron de cerca los desastres de las contiendas bélicas y bebieron de la corriente existencialista, encontrando en el pensamiento de Nietzsche la respuesta a sus más profundas reflexiones. También la herencia de los clásicos y de la catarsis del antiguo drama ático dejó profundas huellas en sus respectivas obras artísticas (Valverde, 2010: 15). Kazantzakis había asistido al estreno de dos de las películas de Cacoyannis en Cannes, a saber, Stella (1955) y La muchacha de negro (To korísi me ta mavra, 1956), y le mostró su deseo de que alguna vez se animase a llevar sus novelas a la pantalla, pero por aquel entonces el director ni siquiera había leído la novela sobre Zorba.

Cuando Michael Cacoyannis se pone a la tarea de la redacción del guion se encuentra con una inmensa obra maestra que tiene que sintetizar subrayando los aspectos más dramáticos y, al mismo tiempo, dándole mayor vitalismo y unas buenas dosis de humor, como queda claro en la azarosa travesía del barco por el Egeo hasta arribar a las costas de Creta (Siafkos, 2009: 142) que vemos en los primeros minutos del largometraje o en las distintas escenas de los obreros en la mina de lignito. En principio podemos hablar de una adaptación muy próxima al texto original, aunque también

\footnotetext{
${ }^{7}$ Según apunta el periodista Christos Siafkos, Burt Lancaster había comprado los derechos de otra novela de Kazantzakis, Capitán Michalis (Kapetán Mijalis, 1953) y propuso a Cacoyannis que este se encargara de preparar una adaptación para el cine dándole el papel protagonista, un proyecto que finalmente no salió adelante (Siafkos,
} 2009: 156). 


\section{Alejandro Valverde García}

con muchas transformaciones. Una de las más importantes es la de cambiar el punto de vista de la narración, que en la novela gira en torno al escritor en crisis, cuyo nombre no se nos revelará, y que en el filme se trasladará indiscutiblemente a la figura de Alexis Zorba, quedando en penumbras el personaje de Basil y todos sus monólogos filosóficos (Kolonias 1995: 34).

Kazantzakis plantea su libro como una serie de reflexiones personales cargadas de muchas notas autobiográficas (Garantoudis, 2008: 54). De hecho, existió un tal Yorgos Zorbás en la vida real. El autor cretense coincidió con él en una estancia en el Monte Atos allá por el año 1914 y hasta tal punto lo impresionó por su vitalidad y su originalidad que este hombre va a marcar un hito en su obra y en su vida personal (Agathos, 2017: 146; Stasinakis, 2017). Cacoyannis, por su parte, es muy respetuoso en la película con el contenido de los diferentes capítulos y da vida a los personajes teniendo en mente a algunos de los actores en la redacción del guion, pero tiene que suprimir los párrafos más metafísicos en los que el autor se plantea qué es el hombre y quién es Dios (Karalis, 2012: 103). Tampoco puede incluir las mil anécdotas que Zorba contará a su patrón durante el tiempo que ambos comparten o el extenso relato de los misterios del monasterio al final del libro, que constituye prácticamente otra novela policíaca dentro del texto principal $^{8}$. Pero lo que sí se traduce a imágenes con total maestría es la descripción de los paisajes y ambientes, que van cambiando siguiendo las distintas estaciones del año y sus principales fiestas (Navidad, Pascua). También queda patente la maestría de Cacoyannis a la hora de trazar el perfil psicológico de todos y cada uno de los personajes, especialmente de los femeninos, como vemos en la escena de la taberna, cuando la viuda Surmelina pretende recuperar a su cabra enfrentándose a los mozos del pueblo ${ }^{9}$. El detalle del paraguas que Basil ofrece a la mujer

${ }^{8}$ En el DVD de la película distribuido por la 20th Century Fox se recupera una secuencia que Cacoyannis terminó borrando en el montaje final. Se trata de un comienzo alternativo en el que, con un tono marcadamente sarcástico, vemos a Dios (Anthony Quinn) en el Paraíso escuchando con paciencia a una chica recién llegada que confiesa todos sus pecados, los cuales quedan inscritos en una pizarra. En la novela Zorba confiesa a su patrón que Dios, si existe, será seguramente como él, compasivo y misericordioso, que borra las faltas de los mortales con una esponja y deja vacío el Infierno. Este sería otro ejemplo de cómo en la película se silencia el elemento religioso, quizás para evitar la censura del film. De cualquier modo, el director ha querido mantener algunos planos y secuencias que permiten sugerir ciertas relaciones homoeróticas y hasta pedófilas entre los monjes griegos, algo que se explicita en la novela de Kazantzakis.

${ }^{9}$ Esta secuencia es analizada minuciosamente por Dietmar Regensburger (2005: 372-376), siguiendo la teoría mimética de René Girard, para ejemplificar cómo la pasión, el amor y el crimen se puede llegar a contagiar entre una colectividad. Así, Zorba, como observador externo, explica al joven Basil que todos los varones del pueblo desean vivamente acostarse con la viuda. Esa es la razón por la que nunca podrán perdonar que esta finalmente admita en su lecho al extranjero. En su estudio 
para que se resguarde de la lluvia, ausente en el libro, lo ha añadido el director para recalcar la gentileza del joven escritor y el origen de un amor que pronto se consumará con trágicas consecuencias (Agathos, 2017: 228). En este sentido también es memorable el momento en el que Irene Papas y Alan Bates se cruzan en el angosto camino, apresurando el paso, deteniéndose después y con una maravillosa composición de planos que demuestra el dominio del ritmo cinematográfico, transmitiendo al espectador ese desasosiego y nerviosismo de unos personajes que luchan en vano por ocultar el fuego de la pasión (Katsan, 2016: 38). Veamos cómo nos lo cuenta Kazantzakis en el comienzo del capítulo 11:

Y, de pronto, me flaquearon las rodillas; por el camino de la aldea, debajo de los olivos, apareció la viuda contoneándose, jacarandosa, bien torneada, con su pañoleta negra. Su andar era sinuoso, como el de una pantera, y tuve la impresión de que dejaba en el aire un acre olor a almizcle. «iSi pudiera huir!», pensé...

$\mathrm{Al}$ igual que el lector de la novela se identifica pronto con el narrador omnisciente, el espectador se ve atrapado desde la primera secuencia por la curiosa pareja formada por Basil y Alexis Zorba. El primero, un escritor de origen cretense que ha perdido la inspiración, representa la cordura y el equilibrio emocional pero no tiene la gracia y el optimismo que derrocha el alocado Zorba. Ambos se complementan perfectamente y este juego de oposición servirá de hilo conductor durante el desarrollo de la narración fílmica. A su alrededor el panorama de la ruda aldea se nos plantea desolador. Los cretenses, toscos, machistas, anclados en las costumbres milenarias, son extremadamente supersticiosos y crueles, hasta el punto de robar todas las pertenencias de la prostituta francesa el día de su muerte y de incitar y aprobar el asesinato de la joven viuda cuyo pecado imperdonable ha sido el de abrir su casa y su corazón al extranjero inglés en vez de acceder a sus numerosos pretendientes (Georgakas, 2005: 30).

Michael Cacoyannis comprende que estas dos escenas, que ocupan en el libro los capítulos 22 y 23, van a ser el eje de su película ${ }^{10}$ y en torno a estas secuencias construirá el resto del filme (Agathos, 2017: 167) siguiendo una narración episódica de forma un tanto artificial (Karalis, 2016: 65). Todo lo demás se nos antoja anecdótico, la evolución de la rehabilitación de la mina de lignito heredada por el joven escritor inglés, el viaje de Zorba a la capital y su romance con la cabaretera Lola o hasta la boda con su Bubulina, Madame Hortense, una de las escenas preferidas por el director. De hecho,

Regensburger establecerá también paralelismos entre este largometraje y Marnie la ladrona (Marnie, 1964) de Alfred Hitchcock y Medea (1969) de Pier Paolo Pasolini.

10 Para un análisis pormenorizado de ambas secuencias, que ejemplifican claramente el uso de la catarsis en la narración cinematográfica de los films de Cacoyannis, ver Valverde (2010), especialmente las páginas 21 y 22. 


\section{Alejandro Valverde García}

una vez que los hombres del pueblo han matado a la viuda ${ }^{11}$, la película se acerca a su punto final sirviendo de anticlímax el gran desastre de los proyectos de Zorba con la caída del teleférico y el famoso baile final de los actores protagonistas en la playa cretense.

Nada vemos de los tres últimos capítulos de la novela, que Cacoyannis considera poco cinematográficos. En su lugar, la resolución de la trama tiene que conducir al espectador a un happy end propio de las antiguas comedias griegas y de los musicales típicos de Hollywood (Basea, 2015: 66). Gracias a esta importante decisión las escenas más trágicas quedan pronto diluidas y la película consigue transmitir al público con gran efectividad el triunfo de la vida y de la alegría, algo bastante lejano del existencialismo (Agathos, 2017: 237). Como demuestra la propia naturaleza, un grano de trigo muere en la tierra para dar a los hombres su fruto y después de la tempestad los cielos se abren y sucede la bonanza, es decir, que después de la muerte existe la resurrección. En este sentido, también se puede interpretar la escena del cruel asesinato de la viuda como la culminación de un arcaico ritual sacrificial por el cual los cretenses, como en las Bacantes de Eurípides, derraman la sangre de su víctima y consiguen con ello la restitución de la paz y de la armonía en la aldea (Regensburger, 2005: 374).

El guion de Zorba el griego reinterpreta, en cierto sentido, el mensaje último del texto de Kazantzakis, al sugerir la idea de que el joven escritor abraza finalmente los ideales de Zorba (Bien, 2000: 164). Pero no debemos olvidar que esta película está dirigida desde su concepción a un público internacional, buscando su rentabilidad comercial ${ }^{12}$, algo que logró de forma evidente (Garantoudis, 2008: 66). Michael Cacoyannis es heredero en su forma de concebir los planos y de dirigir su cámara del expresionismo alemán y del neorrealismo italiano, como ya había demostrado en sus primeras producciones cinematográficas, pero no es menos cierto que sobre él pesa también el estilo más clásico de los filmes de Hollywood que él tanto admiró desde niño. Nuestra película plantea ciertos problemas a la hora de clasificarla dentro de un género cinematográfico concreto precisamente por esa mezcla de estilos y de tonos (Basea, 2015: 60), aunque consideramos que quizás esa fusión fuera al fin y al cabo una de las claves de su éxito arrollador.

En el propio título del filme podemos detectar una marcada ironía ya que el protagonista ni es realmente griego ni es representativo de aquella nacionalidad. Todo lo contrario, Alexis Zorba es más bien un hombre libre y apátrida, un aventurero cosmopolita de origen macedonio que andará errante por Rumanía, Rusia o Serbia guiado siempre por su propia ética y

\footnotetext{
${ }^{11}$ En el libro leemos, de una forma mucho más explícita, que el terrateniente Mavrandonis, para vengar la muerte de su hijo Pavlos, que se ha suicidado arrojándose al mar, secciona la cabeza de la viuda y la arroja hacia la Iglesia.

${ }^{12}$ Según la base de datos de IMDb, el presupuesto de la película no alcanzó los 800.000 dólares y, sin embargo, logró recaudar más de 23 millones.
} 
religión (Garantoudis, 2008: 64). Tampoco los cretenses salen muy bien parados en su caracterización como una civilización tosca y atrasada, pero funcionan como el contrapunto perfecto a la figura de Basil, el joven extranjero, que representa la educación y la modernidad de Occidente. Desde el comienzo de la película, con los títulos de crédito impresos sobre el avión, hasta ese final apoteósico con la cámara alejándose de la playa al compás del syrtaki de Theodorakis, todo parece estar invitando al espectador a visitar esas tierras llenas de placeres exóticos y de restos arqueológicos, donde podrá disfrutar de la comida, de la bebida y de bailes tradicionales (Basea, 2015: 62). Lo que seguramente sorprendería a los miles de turistas que a partir de entonces visitaron Grecia sería descubrir que la famosa danza de Zorba es otro de los inventos de la película, creado a partir de la combinación del syrtos, una danza tradicional cretense, y del jasápiko, mientras que el tema musical, basado en la canción Strose to stroma su yia dyo, se adscribe al rebétiko, un género musical de fuertes connotaciones políticas y símbolos que nos hablan del triunfo de la improvisación y de la libertad del cuerpo y del alma (Zografou, 2007: 117). Es decir, que bajo las notas musicales de Mikis Theodorakis subyace también un mensaje subliminal muy interesante de protesta contra los regímenes políticos dictatoriales (Karalis, 2012: 104), como el del general Ioannis Metaxás (1936-1941) o la propia Dictadura de los Coroneles (1967-1974), que perseguirá con furia al compositor griego unos pocos años después.

El rodaje comienza, con gran despliegue de periodistas y medios de comunicación, en la primavera del año 1964 en la isla de Creta, como no podía ser de otro modo (Agathos, 2007: 92), contando con un presupuesto generoso ofrecido desde Hollywood por los ejecutivos de la 20th Century Fox $^{13}$. Según recordaba el propio director en varias entrevistas, el éxito mundial de Electra le abrió tantas puertas que ya antes de empezar a filmar Zorba el griego se daba por supuesto que se convertiría en un hito cinematográfico y que llegaría a las puertas de los Oscar (Siafkos, 2009: 136). Desde el primer momento tuvo claro que el protagonista no podía ser otro que Anthony Quinn, aunque con el papel de Madame Hortense tuvo ciertas dudas. De hecho, hizo volar en avión desde París a Atenas a la actriz francesa Simone Signoret, su primera opción, pero en cuanto comenzaron los ensayos de la primera secuencia ambos estuvieron de acuerdo en que ella no era la más adecuada para dar vida a la vieja prostituta. El productor Darryl Zanuck le propuso entonces el nombre de la italiana Anna Magnani. También se hablaba de la actriz griega Despo Diamantidou o de Bette Davis. Anthony Quinn, por lo visto, propuso a Barbara Stanwyck, Ann Sothern y Tallulah Bankhead (Agathos, 2007: 93), pero Cacoyannis, casi a última

${ }^{13}$ El profesor Thanasis Agathos explica la génesis del rodaje según las notas de la prensa local griega (2017: 170-175) y aporta numerosos datos sobre las críticas recibidas por la película tanto en USA (2017: 175-183) como en Grecia (2017: 184197). 


\section{Alejandro Valverde García}

hora, apostó por una actriz de origen ruso que procedía del teatro y que no sabía prácticamente nada de inglés, Lila Kedrova (Triantafyllides, 2014: 62). Esta hizo suyo el papel desde el primer momento, ofreciendo una soberbia interpretación que será elogiada posteriormente por todos los críticos cinematográficos. Además, se incorporarán al rodaje Alan Bates, para encarnar al joven escritor británico Basil, e Irene Papas, cuya presencia llenará la pantalla en las últimas escenas de la película sin tener que hablar prácticamente en todo el filme ${ }^{14}$. Ella es sin duda el vínculo que traslada rápidamente al espectador al mundo de las antiguas tragedias griegas. Por su parte, el director recurrirá frecuentemente a los primeros planos de los ojos de la actriz, que logran transmitir perfectamente la belleza y la sensualidad de una figura trágica enfrentada a un mundo dominado por los hombres (Katsan, 2016: 37).

Junto a ellos el resto del reparto será seleccionado entre actores griegos que accederán a rodar en inglés, si bien tampoco ellos tendrán que memorizar demasiadas frases, como Sotiris Moustakas, pariente lejano del padre de Cacoyannis, que debuta en el cine con su interpretación entrañable de Mimizós, el tonto del pueblo (Valverde, 2012: 165), y que desarrollará posteriormente una dilatada carrera artística en cine, teatro y televisión como actor cómico (Triantafyllides, 2014: 69). De igual forma reconocemos a Yorgos Foundas en el papel de Mavrandonis y a Takis Emmanuíl como Manólakas, principales instigadores del odio visceral hacia la viuda ${ }^{15}$.

Otros de los puntos fuertes del filme, como se demostrará tras su estreno en Estados Unidos, el 17 de diciembre de 1964 en el Sutton de Nueva York, con las primeras críticas de Bosley Crowther en The New York Times, serán la fotografía de Walter Lassally, la banda sonora de Theodorakis, el sonido de Mikes Damalas (el mejor ingeniero de sonido en opinión de la actriz Katharine Hepburn) y los sets y el vestuario diseñados

${ }^{14}$ Alan Bates volverá a trabajar a las órdenes de Michael Cacoyannis, al final de sus respectivas carreras artísticas, en El jardín de los cerezos (O Vissinókypos, 1999), además de prestar su voz en el único telefilm dirigido por Cacoyannis, La historia de Jacob y José (The Story of Jacob and Joseph, 1974). Por su parte, Irene Papas completará con el director chipriota la trilogía basada en las tragedias de Eurípides, encarnando a la Helena de Las troyanas (The Trojan Women, 1971) y a la Clitemnestra de Ifigenia (Ifiyénia, 1977). Sus dos últimos trabajos juntos serán el fallido film político Dulce país (Sweet Country, 1986), en el que se arremete contra la dictadura de Pinochet, y Pano, kato ke playíos (1992), una bufonada coral en la que Cacoyannis vuelve a hacer sonar el famoso tema musical de Zorba compuesto por Theodorakis, como ya había hecho anteriormente en The day the fish came out (1967).

15 Yorgos Foundas había protagonizado el segundo film de Cacoyannis, Stella (1955) y el público norteamericano lo recordaba por su papel en Nunca en Domingo (1960), donde volvía a hacer pareja con la actriz Melina Mercouri. En cuanto a Takis Emmanuíl, Cacoyannis le había dado un breve papel en Electra (1962), donde interpretaba a Pílades, el fiel amigo de Orestes y futuro esposo de la protagonista. 
por el joven escenógrafo griego Vassilis Fotopoulos con la colaboración de su hermano Dionysis (Agathos, 2007: 95). Los componentes de este equipo técnico, habituales colaboradores de Cacoyannis en películas y en representaciones teatrales anteriores, constituirán una gran familia que trabajará codo con codo para que el resultado sea el deseado por el director ${ }^{16}$.

Zorba el griego se presenta ante el público como una obra de arte perfecta, aunque algo previsible y no del todo genuina, en el sentido de que está cargada de tópicos sobre Grecia y sus gentes (Valverde, 2012: 167), algo que algunos críticos cinematográficos griegos le echarán en cara a Michael Cacoyannis tras el estreno de la película el 15 de marzo de 1965 en Atenas ${ }^{17}$. En la película vemos cómo Zorba difama a los cretenses una y otra vez, dando una imagen de los lugareños exageradamente negativa (Agathos, 2007: 111). También las muertes de Madame Hortense y de la viuda están filmadas con excesivo realismo. Pero la propia mujer de Nikos Kazantzakis, Eleni, saldrá en defensa del director aclarando que esa representación del pueblo cretense no era ninguna novedad, sino que ya estaba en la novela de su marido (Triantafyllides, 2014: 19), como podemos leer en el episodio de la muerte de la viuda al comienzo del capítulo 22:

Unos se lanzaron junto con el guarda forestal a la iglesia, otros, desde arriba, le tiraban piedras. Una piedra le dio en el hombro. La viuda dejó escapar un grito; se cubrió el rostro con las manos, corrió, encorvada, intentando huir. Pero los jóvenes ya habían llegado a la puerta de la iglesia y Manólakas había sacado el cuchillo... Alineadas en la plaza, las muchachas mordisqueaban sus pañuelos blancos; las viejas, encaramadas en las vallas, chillaban: «¡Matadla! ¡Matadla!».

En lo que sí habrá unanimidad será en el elogio al desarrollo de los caracteres femeninos del filme, algo en lo que Michael Cacoyannis, como el George Cukor griego, ya había demostrado sobradamente que era un auténtico maestro. Ahí estaban, para confirmarlo, sus inmortales heroínas modernas de ficción Stella, la Marina de La muchacha de negro o Electra, con las que había impulsado las carreras artísticas de Melina Mercouri, Elli Lambetti e Irene Papas, respectivamente. El asesinato público de la viuda nos presenta elementos recurrentes que ya había empleado el director en algunas de sus anteriores películas. Así, igual que veíamos en Electra, tenemos una víctima acorralada destinada a una muerte segura, sin que un héroe pueda acudir a tiempo de socorrerla, y esta situación límite llegará a su clímax en una escena que el espectador tendrá que reconstruir

${ }^{16}$ Los distintos sets y diseños del vestuario pueden admirarse en el lujoso volumen editado por el Museo Benaki de Atenas en honor del escenógrafo Vassilis Fotopoulos (2007: 88-101).

${ }^{17}$ El estreno de la película en España tuvo lugar el 25 de octubre de 1965 con muy buena crítica en el diario $A B C$. 


\section{Alejandro Valverde García}

mentalmente porque las muertes nunca se muestran frente a la cámara, como sucedía en la representación de las antiguas tragedias griegas (Valverde, 2010: 21); como en La muchacha de negro, los movimientos vertiginosos de la cámara acentuarán la opresión de una colectividad que funcionará como un coro trágico (Basea, 2015: 69); y, finalmente, ese lento y silencioso recorrido final hacia la muerte, filmando la escena con la cámara al hombro, nos recuerda el final de Stella, en la que la protagonista muere curiosamente a manos de un joven cretense (Hadjikyriacou, 2015: 235). Y es que, en definitiva, todas las heroínas de los filmes de Cacoyannis se ven enfrentadas a un mundo dominado por los hombres, quedando estos envilecidos en un sombrío segundo plano (Agathos, 2017: 236).

Frente al cine tradicional que los estudios norteamericanos ofrecían al público en ese momento, Zorba el griego va a suponer el triunfo del cine independiente (Basea, 2015: 70), aunando realismo y utopía, cine de autor y de entretenimiento, tragedia y comedia. El éxito en taquilla tanto en Estados Unidos como en Europa, siguiendo de cerca a la superproducción de la 20th Century Fox Cleopatra (Joseph L. Mankiewicz, 1963), va a suponer la promoción a nivel internacional de la novela de Nikos Kazantzakis y de todo el equipo de filmación, aumentando el turismo en Grecia, lo cual supuso una potente inyección económica que lógicamente no se desperdició (Agathos, 2007: 152). Y cuando Michael Cacoyannis estaba en la cima de su carrera artística no se le ocurre otra cosa mejor que convertirse en un nuevo Zorba y atreverse a atacar a los Estados Unidos filmando en 1967 The day the fish came out, una sátira contra el armamento nuclear y los peligros de la contaminación (Kolonias, 1995: 14) con un estilo marcadamente teatral y mucho menos cinematográfico (Karalis, 2016: 66). Como es lógico, su carrera en el cine no volverá ya a remontar el vuelo, pero él mismo, siguiendo los pasos de su querido Zorba, hallará en la exaltación de la alegría un camino seguro hacia la libertad (Valverde, 2010: 23).

En una ocasión mi gran amiga Selma Ancira, la mejor traductora de las novelas de Nikos Kazantzakis al español, me comentó una anécdota que me pareció entrañable. Un buen día se propuso localizar a Walter Lassally para hacerle una entrevista, ardua tarea porque el ilustre director de fotografía no usaba el correo electrónico ni tenía conexión a Internet. Sorprendentemente, se había ido a vivir justo a las cercanías de la playa de Stavros, donde habían rodado cincuenta años antes la escena final de Zorba el griego. Para contactar con él tuvo que recurrir a una llamada telefónica a la taberna donde este iba a diario a comer. Al final lo consiguió y concertaron la ansiada cita. Fue a verlo personalmente a suelo cretense y allí se encontró a un hombre de edad avanzada pero envidiablemente jovial y humilde. Después de enviudar y de haber desarrollado una carrera profesional inmejorable, saboreando los laureles del éxito, había decidido pasar sus últimos días en aquel apartado lugar del Mediterráneo. A él Zorba también le había enseñado que los mayores placeres de esta vida muchas veces se encuentran en las cosas más sencillas... 


\section{Bibliografía CITADA}

Agathos, Thanasis (2007), Apó to "Bíos kai Poleitía tou Aléxi Zormpá» sto "Zorba the Greek», Atenas, Aigókeros.

Agathos, Thanasis (2017), Níkos Kazantzakis ston kinimatografo, Atenas, Gutenberg.

BASEA, Erato (2015), «Zorba the Greek, Sixties exotica and a new cinema in Hollywood and Greece», en Studies in European Cinema, Londres, Routledge, págs. 60-76 [en línea: https://www.tandfonline.com/doi/abs/10.1080/17411548.2015.1 015830. Fecha de consulta 02/03/2020].

BIEN, Peter (2000), «Nikos Kazantzakis's Novels on Film», Journal of Modern Greek Studies, 18/1, págs. 161-169.

Fotopoulos, Vassilis (2007), Vassilis Fotopoulos, Atenas, Museo Benaki.

GaRANTOUDIS, Evripidis (2008), «Zorba the Greek tou Mijali Kakogianni kai Bíos kai Politeía tou Alexi Zormpá tou Níkou Kazantzaki: mia sýnkrisi ypó ti skiá tis próslipsis tou kazantzakikoú érgou», Comparaison, 19, págs. 50-84 [en línea: http://rdo.upatras.gr/v1/public/files/440/file109.pdf. Fecha de consulta 02/03/2020].

GeorgaKas, Dan (2005), «From Stella to Iphigenia: The woman-centered films of Michael Cacoyannis», Cineaste, 30/2, págs. 24-30.

HadjiKYRIACOU, Achilleas (2015), Masculinity and gender in Greek Cinema 1949-1967, Nueva York/Londres, Bloomsbury.

Karalis, Vrasidas (2012), A History of Greek Cinema, Londres/Nueva York, Continuum.

Karalis, Vrasidas (2016), Realism in Greek Cinema. From the post-war period to the present, Londres/Nueva York, I. B. Tauris.

Katsan, Gerasimus (2016), «The Hollywood Films of Irene Papas», Journal of Modern Hellenism, 32, págs. 31-43 [en línea: http://journals.sfu.ca/jmh/index.php/jmh/article/viewFile/294/2 96. Fecha de consulta 02/03/2020].

KaZANTZAKIS, Nikos (2015), Zorba el griego (Vida y andanzas de Alexis Zorba), trad. de Selma Ancira, Barcelona, Acantilado.

Kolonias, Babis (1995), Mijalis Kakoyiannis. 36º Festival Kinimatografou Thessaloníkis, Atenas, Kastanioti.

Mitropoulos, Aglae (1968), Découverte du cinema grec, París, Seghers.

Regensburger, Dietmar (2005), «Are You Still in the Mood for Killing?: Mimetic Rivalry, Scapegoating and Sacrifice in Hitchcock's Marnie, Cacoyannis' Zorba the Greek and Pasolini's Medea», en W. Palaver (ed.), Passions in Economy, Politics and the Media: In Discussion with Christian Theology. Beiträgezurmimetischen Theorie 17, Vienna, Lit Verlag, págs. 363-385.

SiAfKos, Jristos (2009), Mijalis Kakoyiannis. Se proto plano, Atenas, Psijóyios. Stasinakis, Yorgos (2017), Kazantzakis-Zormpas. Mia aliziní filía, Atenas, Kastanioti. 
TAYLOR, Timothy W. (1980), «Kazantzakis and the Cinema», Byzantine and Modern Greek Studies, 6, págs. 157-168 [en línea: https://www.cambridge.org/core/journals/byzantine-and-modern-greekstudies/article/kazantzakis-and-thecinema/AE9F7F0E9AE0AA45A1CC3A3B2C413548. Fecha de consulta 02/03/2020].

Triantafyllides, Jason (2014), Michael Cacoyannis talks to Jason Triantafyllides, Atenas, Andy's Publishers.

VAlverde, Alejandro (2010), «La catarsis en la filmografía de Michael Cacoyannis», en F. Salvador Ventura (ed.), Cine y cosmopolitismo. Aproximaciones transdisciplinares a imaginarios visuales cosmopolitas, Santa Cruz de Tenerife, Intramar, págs. 11-24.

VALVERDE, Alejandro (2012), «Michael Cacoyannis, la sabiduría de la simplicidad», en F. Salvador Ventura (ed.), Cine y autor. Reflexiones sobre la teoría y la praxis de creadores fílmicos, Santa Cruz de Tenerife, Intramar, págs. 155-168.

VALVERDE, Alejandro (2013), «Actualización bibliográfica sobre la filmografía de Michael Cacoyannis», Estudios neogriegos, 15, págs. 191-206.

Zografou, Magda y Mimima Pateraki (2007), «The invisible dimension of Zorba's dance», Yearbook for Traditional Music, 39, págs. 117-131.

Fecha de recepción: 28/05/2020.

Fecha de aceptación: 25/07/2020. 